\title{
Analisis Variabel-Variabel Risiko pada Pelaksanaan Proyek Konstruksi Jalan
}

\author{
Rahmi Hidayati, Monika Natalia, Fauna Adibroto, Mafriyal, Yurisman , Rizkina Saskia \\ Jurusan Teknik Sipil, Politeknik Negeri Padang \\ Email :rhidayati1974@gmail.com, monikanatalia75@gmail.com, fauna_adibroto@yahoo.com, \\ mafriyalmuluk60@gmail.com, yurisman_pdg@yahoo.com, rizkinasaskia@yahoo.co.id
}

\begin{abstract}
This research aims to identify the risk variables that ever occurred while executing of road construction project. In addition, it is to identify how significant and how big the influence of risk variables to the articulation of project execution processes of a road construction project, based on questionnaire that distributed to 30 questionnaires who are project managers and site managers on contractors of road construction project. From the research data, there were identified 14 risk variables with 84 risk sub-variables on execution of road construction project. Those 14 risk variables were natural, social, politic, economic, law, occupational safety and health, managerial, technical, cultural, logistic, condition around construction site, design and technology, labor, and contractual variables. From the data analysis by using SPSS version 16, obtained there were 14 risk sub-variables which became the most influential sub-variables (indicators) to the road construction project. All sub-variables on the questionnaire are valid and reliable. The results of this research is expected to be considered for all parties involved in the construction project to pay more attention to risk variables during the execution of road construction project.
\end{abstract}

Keywords: Risk Variables; Road Construction Project

\section{PENDAHULUAN}

Risiko merupakan sesuatu yang tidak diharapkan, seperti kehilangan, bahaya dan konsekuensi kerugian lainnya. Kemungkinan kerugian tersebut merupakan bentuk ketidakpastian yang harusnya dipahami secara efektif serta diusahakan untuk menghindarinya, sebagai bagian dari strategi dari manajemen risiko untuk minimalisir kerugian pada proyek konstruksi jalan.

Semua pihak yang terlibat di proyek konstruksi harus menyadari pentingnya memahami permasalahan risiko yang dihadapi, karena kesalahan dalam memperkirakan risiko atau kesalahan menangani risiko akan menimbulkan dampak negatif baik langsung maupun tidak langsung pada proyek konstruksi (Labombang, 2011).

Semakin tinggi tingkat kompleksitas suatu proyek maka semakin besar kemungkinan tingkat risiko yang ditanggung
Analisa risiko ini diperlukan untuk menghindari/mengantisipasi sedini mungkin, kejadian tak terduga yang mungkin merugikan, serta berdampak pada efisiensi dan efektifitas pelaksanaan proyek. Seandainya risiko itu terjadi, semua pihak terkait pada pelaksanaan proyek jalan dapat bertindak cepat dengan memberi solusi terbaik.

Tujuan penelitian ini adalah;

1. Mengidentifikasi variabel-variabel risiko pada pelaksanaan proyek konstruksi jalan.

2. Mengetahui variabel-variabel risiko yang mempunyai pengaruh tertinggi terhadap pelaksanaan proyek konstruksi jalan.

3. Menghitung nilai rata-rata (mean) pada analisa deskriptif, untuk mengetahui seberapa besar pengaruh dari variabelvariabel risiko pada pelaksanaan proyek konstruksi jalan.

oleh pelaksana proyek konstruksi tersebut (Syaranamual et al, 2014). Sedangkan Barrie and Paulson (1995), menjelaskan bahwa risiko 
yang terjadi pada proyek adalah hal-hal yang jika terjadi dapat berpengaruh buruk pada sasaran proyek. Sasaran utama proyek adalah jadwal, biaya dan spesifikasi teknis (mutu) sesuai kontrak. Artinya, jika risiko terjadi, akan berdampak pada terganggunya kinerja pelaksanaan proyek secara keseluruhan. Akibatnya, akan merugikan semua pihak yang terlibat di proyek, seperti owner, konsultan pengawas, kontraktor dan masyarakat di sekitar lokasi proyek. Untuk meminimalir terjadinya suatu risiko, perlu dilakukan identifikasi variabel-variabel risiko pada pelaksanaan proyek konstruksi jalan.

\section{TINJAUAN PUSTAKA}

Risiko adalah sesuatu yang mengarah pada ketidakpastian mengenai terjadinya suatu peristiwa selama selang waktu tertentu, yang dapat menyebabkan kerugian, baik kerugian yang tidak berarti maupun kerugian besar. Secara umum risiko dikaitkan dengan kemungkinan (probabilitas) terjadinya peristiwa diluar yang diharapkan (Soeharto, 1995).

Manajemen risiko merupakan pendekatan yang dilakukan terhadap risiko, yaitu dengan memahami, identifikasi dan mengevaluasi risiko suatu proyek. Kemudian mempertimbangkan tindakan yang akan dilakukan terhadap dampak yang ditimbulkan dan kemungkinan pengalihan risiko kepada pihak lain atau mengurangi risiko yang terjadi (Labombang, 2011).

Menurut Rahmanita et al (2014), proses identifikasi risiko merupakan proses menentukan risiko-risiko yang mungkin akan memberikan efek terhadap pelaksanaan proyek konstruksi, serta mendokumentasikan risiko-risiko yang telah teridentifikasi tersebut. Tahap identifikasi merupakan tahap paling penting, karena seluruh proses kegiatan selama life-cycle proyek dapat diketahui, dan diperiksa pada bagian bagian yang potensial akan terjadinya risiko (risk exposure).

Sedangkan Astiti (2014) menjelaskan, identifikasi risiko merupakan tahap tersulit dan paling menentukan dalam manajemen risiko. Kesulitan identifikasi risiko disebabkan oleh ketidakmampuan untuk mengidentifikasi seluruh risiko yang mungkin akan timbul, mengingat adanya ketidakpastian dari apa yang dihadapi. Dalam identifikasi risiko yang mungkin terjadi di pelaksanaan proyek konstruksi jalan, terlebih dahulu diupayakan untuk menentukan sumber risiko dan efek risiko secara komprehensif.

Salah satu hasil kajian risiko yang pernah dilakukan, Sandhyavitri dan Zulfiqar (2014) menyimpulkan pada penelitiannya, bahwa "analisis risiko dan mitigasi risiko perlu untuk dilaksanakan dalam proyek konstruksi jalan tol, karena dapat mengefisienkan dana dalam jumlah yang relatif signifikan".

Sedangkan hasil analisis penelitian Syaranamual et al (2014), menyimpulkan bahwa "faktor penyebab risiko yang menentukan keberhasilan suatu proyek konstruksi adalah: risiko finansial, risiko bencana alam, risiko hukum, dan risiko sumber daya, dimana risiko konstruksi ini berpengaruh dengan nilai yang sama terhadap keberhasilan proyek konstruksi". 


\section{METODE PENELITIAN}

\subsection{Questionnaire Based Research}

Penelitian ini menggunakan

Questionnaire Based Research. Questionnaire didistribusikan ke 11 orang project manager dan 19 orang site manager pada kontraktor proyek konstruksi jalan yang memiliki kantor di kota Padang (Sumatera Barat). Project manager dan site manager dipilih sebagai responden, karena memiliki kewajiban untuk memikirkan risk management, serta pengambil keputusan setiap kebijaksanaan pada pelaksanaan proyek konstruksi jalan. Pengolahan data dengan menggunakan SPSS ver 16. Diagram alir penelitian ini dapat dilihat pada Gambar 1.

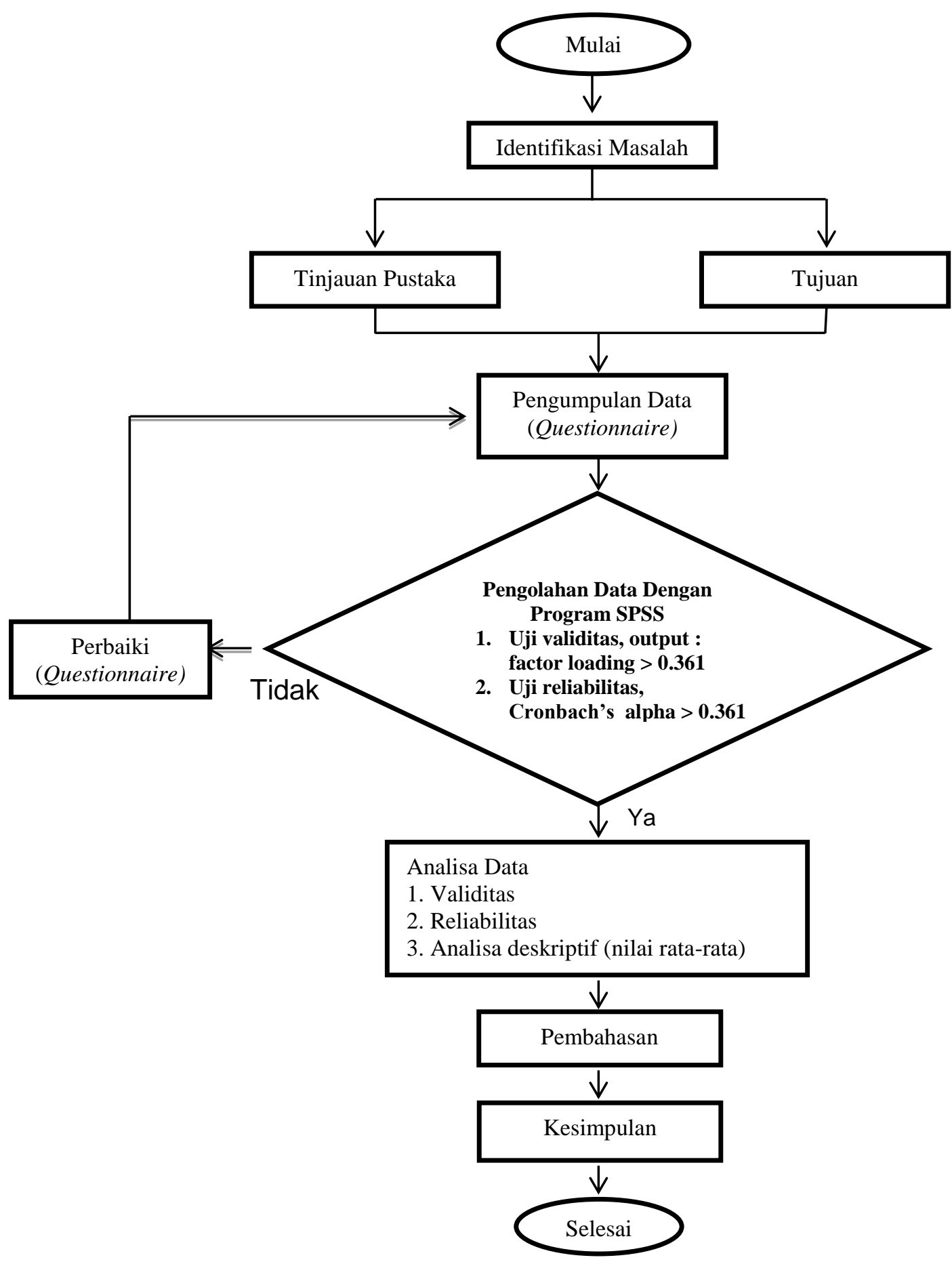

Gambar 1. Diagram Alir Penelitian 


\subsection{List of Questionnaire}

Tabel 1. List if Questionnaire

\begin{tabular}{|c|c|c|c|}
\hline No & Variabel Risiko & Sub Variabel Risiko (Indikator) & $\begin{array}{l}\text { Variabel } \\
\text { Bebas }\end{array}$ \\
\hline \multirow{6}{*}{1.} & \multirow{6}{*}{ Alam/Natural } & Angin badai & $\mathrm{X}_{1.1}$ \\
\hline & & Hujan & $\mathrm{X}_{1.2}$ \\
\hline & & Banjir & $\mathrm{X}_{1.3}$ \\
\hline & & Gempa bumi & $\mathrm{X}_{1.4}$ \\
\hline & & Cuaca tidak menentu & $\mathrm{X}_{1.5}$ \\
\hline & & Tanah longsor & $\mathrm{X}_{1.6}$ \\
\hline \multirow{4}{*}{2.} & \multirow{4}{*}{ Sosial } & Gangguan keamanan di lokasi proyek & $X_{2.1}$ \\
\hline & & $\begin{array}{lllll}\begin{array}{l}\text { Masalah lahan/pembebasan lahan } \\
\text { direncanakan }\end{array} & \text { area proyek yang } \\
\end{array}$ & $\mathrm{X}_{2.2}$ \\
\hline & & Pungutan liar oleh preman di sekitar proyek & $\mathrm{X}_{2.3}$ \\
\hline & & Pencurian material dan peralatan kerja di lokasi proyek & $\mathrm{X}_{2.4}$ \\
\hline \multirow{4}{*}{3.} & \multirow{4}{*}{ Politik } & Kerusuhan atau huru hara masyarakat setempat & $X_{3.1}$ \\
\hline & & Demonstrasi yang dilakukan oleh masyarakat sekitar proyek & $X_{3.2}$ \\
\hline & & Ada perubahan kebijakan politik atau kebijakan pemerintah & $X_{3.3}$ \\
\hline & & Aksi mogok kerja oleh pekerja di lapangan & $X_{3.4}$ \\
\hline \multirow{5}{*}{4.} & \multirow{5}{*}{ Ekonomi } & Finansial/kondisi dana dari owner tidak lancar & $\mathrm{X}_{4.1}$ \\
\hline & & Inflasi di Indonesia & $\mathrm{X}_{4.2}$ \\
\hline & & Kenaikan suku bunga pinjaman oleh bank & $\mathrm{X}_{4.3}$ \\
\hline & & $\begin{array}{l}\text { Kenaikan BBM (bahan bakar minyak) dan TDL (tarif dasar listrik) } \\
\text { pada saat pelaksanaan proyek }\end{array}$ & $\mathrm{X}_{4.4}$ \\
\hline & & $\begin{array}{l}\text { Aliran dana pelaksanaan proyek dari manajemen keuangan } \\
\text { kontraktor tidak lancer }\end{array}$ & $\mathrm{X}_{4.5}$ \\
\hline \multirow{5}{*}{5.} & \multirow{5}{*}{$\begin{array}{l}\text { Undang- } \\
\text { undang }\end{array}$} & Tidak terpenuhinya kondisi dan persyaratan hukum/peraturan & $X_{5.1}$ \\
\hline & & $\begin{array}{l}\text { Kesulitan prosedur dalam menerapkan peraturan perijinan/UU } \\
\text { jasa konstruksi }\end{array}$ & $X_{5.2}$ \\
\hline & & Perselisihan terhadap pasal-pasal kontrak & $X_{5.3}$ \\
\hline & & Sengketa antara pihak-pihak yang terkait dalam kontrak & $X_{5.4}$ \\
\hline & & Perubahan peraturan pemerintah/hukum perdagangan & $X_{5.5}$ \\
\hline \multirow{9}{*}{6.} & \multirow{9}{*}{$\begin{array}{l}\text { Keselamatan } \\
\text { dan } \\
\text { Kesehatan } \\
\text { Kerja (K3) }\end{array}$} & Perawatan/jaminan kesehatan untuk pekerja & $X_{6.1}$ \\
\hline & & Efek/akibat melakukan kegiatan konstruksi & $X_{6.2}$ \\
\hline & & Fasilitas kesehatan untuk tenaga kerja & $X_{6.3}$ \\
\hline & & $\begin{array}{l}\text { Fasilitas air bersih/listrik/dapur/tempat tinggal pekerja di } \\
\text { lapangan }\end{array}$ & $X_{6.4}$ \\
\hline & & $\begin{array}{l}\text { Ketersediaan asuransi tenaga keja/asuransi kesehatan untuk } \\
\text { tenaga kerja }\end{array}$ & $X_{6.5}$ \\
\hline & & $\begin{array}{l}\text { Kurangnya kesadaran pekerja proyek untuk mematuhi aturan } \\
\text { keselamatan dan kesehatan kerja }\end{array}$ & $X_{6.6}$ \\
\hline & & $\begin{array}{l}\text { Adanya pekerja yang sakit atau mengalami kecelakaan hingga } \\
\text { terjadi kematian }\end{array}$ & $X_{6.7}$ \\
\hline & & $\begin{array}{l}\text { Epidemik atau wabah penyakit menular akibat melakukan } \\
\text { kegiatan konstruksi }\end{array}$ & $X_{6.8}$ \\
\hline & & $\begin{array}{l}\text { Kurangnya perhatian kontraktor dalam menyediakan fasilitas } \\
\text { keselamatan dan kesehatan kerja, misalnya alat pelindung diri } \\
\text { yang kurang lengkap }\end{array}$ & $X_{6.9}$ \\
\hline \multirow{8}{*}{7.} & \multirow{8}{*}{ Manajerial } & Waktu pelaksanaan pekerjaan kurang memadai di lapangan & $\mathrm{X}_{7.1}$ \\
\hline & & $\begin{array}{l}\text { Adanya perbedaan beberapa design konsultan perencana } \\
\text { dengan kondisi di lapangan }\end{array}$ & $X_{7.2}$ \\
\hline & & Survey yang dilakukan pada saat design tidak lengkap & $\mathrm{X}_{7.3}$ \\
\hline & & Ketetapan pekerjaan konstruksi (jadwal dan kualitas) & $\mathrm{X}_{7.4}$ \\
\hline & & Tidak diterimanya pekerjaan konstruksi oleh owner & $\mathrm{X}_{7.5}$ \\
\hline & & Kurang terperinci job description di pelaksanaan proyek & $\mathrm{X}_{7.6}$ \\
\hline & & Tidak lengkapnya laporan administrasi proyek & $\mathrm{X}_{7.7}$ \\
\hline & & $\begin{array}{l}\text { Pengajuan klaim atas hasil pekerjaan yang tidak sesuai dengan } \\
\text { kontrak }\end{array}$ & $\mathrm{X}_{7.8}$ \\
\hline
\end{tabular}


Tabel 1. Lanjutan

\begin{tabular}{|c|c|c|c|}
\hline No & Variabel Risiko & Sub Variabel Risiko (Indikator) & $\begin{array}{l}\text { Variabel } \\
\text { Bebas }\end{array}$ \\
\hline \multirow[t]{2}{*}{7.} & \multirow[t]{2}{*}{ Manajerial } & $\begin{array}{l}\text { Kemampuan kontraktor yang rendah dalam melaksanakan } \\
\text { proyek kontruksi }\end{array}$ & $\mathrm{X}_{7.9}$ \\
\hline & & Terhambatnya keuangan pihak kontraktor & $\mathrm{X}_{7.10}$ \\
\hline \multirow{11}{*}{8.} & \multirow{11}{*}{ Teknis } & $\begin{array}{l}\text { Kesalahan pemilihan metode pelaksanaan konstruksi jalan di } \\
\text { lapangan }\end{array}$ & $X_{8.1}$ \\
\hline & & $\begin{array}{l}\text { Ketersediaan material yang sampai di lapangan berbeda dengan } \\
\text { yang dipesan }\end{array}$ & $X_{8.2}$ \\
\hline & & Kualitas/kondisi pekerjaan perkerasan eksisting jelek & $\mathrm{X}_{8.3}$ \\
\hline & & Kesalahan inspeksi jalan & $X_{8.4}$ \\
\hline & & $\begin{array}{l}\begin{array}{l}\text { Kesalahan dalam memprediksi kerusakan aset yang ada } \\
\text { dikontrak }\end{array} \\
\end{array}$ & $X_{8.5}$ \\
\hline & & Kondisi jalan dalam kondisi muka air naik & $\mathrm{X}_{8.6}$ \\
\hline & & $\begin{array}{l}\text { Kondisi darurat (misal: cuaca buruk, banjir, kecelakaan, } \\
\text { tumpahan muatan kendaraan) }\end{array}$ & $\mathrm{X}_{8.7}$ \\
\hline & & $\begin{array}{l}\text { Timbulnya kemacetan di sekitar lokasi proyek pelaksanaan } \\
\text { konstruksi jalan }\end{array}$ & $\mathrm{X}_{8.8}$ \\
\hline & & $\begin{array}{l}\text { Kondisi menuju lokasi pelaksanaan konstruksi jalan sangat sulit } \\
\text { (daerah pedalaman) }\end{array}$ & $\mathrm{X}_{8.9}$ \\
\hline & & $\begin{array}{l}\text { Kerusakan infrastruktur yang terjadi di daerah sekitar pada saat } \\
\text { pelaksanaan peningkatan proyek }\end{array}$ & $X_{8.10}$ \\
\hline & & $\begin{array}{l}\text { Kondisi masyarakat yang kurang memperhatikan rambu-rambu } \\
\text { peringatan untuk tidak melintasi jalan yang baru diperbaiki }\end{array}$ & $X_{8.11}$ \\
\hline \multirow{4}{*}{9.} & \multirow{4}{*}{ Budaya } & $\begin{array}{l}\text { Komunikasi antara pengawas dengan pekerja kurang efektif } \\
\text { pada saat pelaksanaan proyek }\end{array}$ & $X_{9.1}$ \\
\hline & & $\begin{array}{l}\text { Perbedaan bahasa dalam hal komunikasi sesama pekerja di } \\
\text { lapangan }\end{array}$ & $X_{9.2}$ \\
\hline & & Perbedaan pendidikan diantara pekerja & $X_{9.3}$ \\
\hline & & Perbedaan dalam cara kerja diantara pekerja & $X_{9.4}$ \\
\hline \multirow{6}{*}{10.} & \multirow{6}{*}{ Logistik } & Keterlambatan kedatangan material & $\mathrm{X}_{10.1}$ \\
\hline & & Kelangkaan produksi material & $\mathrm{X}_{10.2}$ \\
\hline & & Lokasi penampungan material terbatas & $\mathrm{X}_{10.3}$ \\
\hline & & $\begin{array}{l}\text { Tidak ada pengecekan pada saat pengadaan alat (seperti } \\
\text { proses mobilisasi) }\end{array}$ & $\mathrm{X}_{10.4}$ \\
\hline & & Kerusakan material dan peralatan kerja di lokasi proyek & $\mathrm{X}_{10.5}$ \\
\hline & & Volume material yang dikirim jumlahnya tidak tepat & $\mathrm{X}_{10.6}$ \\
\hline \multirow{5}{*}{11.} & \multirow{5}{*}{$\begin{array}{l}\text { Lingkungan } \\
\text { (Kondisi di } \\
\text { Sekitar Lokasi } \\
\text { Proyek) }\end{array}$} & $\begin{array}{l}\text { Terganggunya kelancaran pekerjaan proyek akibat tingginya } \\
\text { tingkat kepadatan lalu lintas di sekitar lokasi proyek }\end{array}$ & $\mathrm{X}_{11.1}$ \\
\hline & & $\begin{array}{l}\text { Terganggunya akses transportasi karena traffic jam di sekitar } \\
\text { lokasi proyek sehingga arus lalu lintas harus dialihkan (system } \\
\text { buka tutup) }\end{array}$ & $\mathrm{X}_{11.2}$ \\
\hline & & $\begin{array}{l}\text { Sulitnya (terbatasnya) akses masuk material dan peralatan ke } \\
\text { lokasi proyek }\end{array}$ & $\mathrm{X}_{11.3}$ \\
\hline & & $\begin{array}{l}\text { Fasilitas infrastruktur di sekitar lokasi proyek tidak memenuhi } \\
\text { kebutuhan untuk aktivitas proyek }\end{array}$ & $\mathrm{X}_{11.4}$ \\
\hline & & Jauhnya lokasi proyek dari daerah keramaian & $\mathrm{X}_{11.5}$ \\
\hline \multirow{3}{*}{12} & \multirow{3}{*}{$\begin{array}{l}\text { Design dan } \\
\text { Technology }\end{array}$} & Adanya kesalahan dalam estimasi biaya & $\mathrm{X}_{12.1}$ \\
\hline & & Owner merubah spesifikasi dan gambar (re-design) & $\mathrm{X}_{12.2}$ \\
\hline & & Perubahan kondisi lapangan (differing site condition) & $\mathrm{X}_{12.3}$ \\
\hline \multirow{6}{*}{13} & \multirow{6}{*}{ Tenaga Kerja } & Tenaga kerja tidak terampil dan produktifitas yang rendah & $\mathrm{X}_{13.1}$ \\
\hline & & Tenaga kerja masuk kerja terlambat dan pulang terlalu cepat & $\mathrm{X}_{13.2}$ \\
\hline & & $\begin{array}{l}\text { Penyediaan fasilitas harian tenaga kerja di lapangan (seperti } \\
\mathrm{km} / \mathrm{wc} \text { ) }\end{array}$ & $\mathrm{X}_{13.3}$ \\
\hline & & Kurang tersedianya jumlah tenaga kerja di lapangan & $\mathrm{X}_{13.4}$ \\
\hline & & Tingkat kedisiplinan tenaga kerja yang rendah & $\mathrm{X}_{13.5}$ \\
\hline & & Kenaikan gaji tenaga kerja yang tidak diharapkan kontraktor & $\mathrm{X}_{13.6}$ \\
\hline
\end{tabular}


Tabel 1. Lanjutan

\begin{tabular}{|l|l|l|c|}
\hline No & Variabel Risiko & Sub Variabel Risiko (Indikator) & $\begin{array}{c}\text { Variabel } \\
\text { Bebas }\end{array}$ \\
\hline \multirow{4}{*}{14.} & \multirow{3}{*}{ Kontraktual } & $\begin{array}{l}\text { Pemutusan kerja sepihak oleh owner, jika kontraktor tidak } \\
\text { melaksanakan kewajiban sesuai kontrak }\end{array}$ & $\mathrm{X}_{14.1}$ \\
\cline { 3 - 4 } & & Terlambatan pembayaran oleh owner & $\mathrm{X}_{14.2}$ \\
\cline { 3 - 4 } & Kurang lengkapnya pasal-pasal dalam kontrak & $\mathrm{X}_{14.3}$ \\
\cline { 3 - 4 } & Perselisihan antara kontraktor dengan owner & $\mathrm{X}_{14.4}$ \\
\cline { 3 - 4 } & Dokumen-dokumen perencanaan yang tidak lengkap & $\mathrm{X}_{14.5}$ \\
\hline
\end{tabular}

Tabel 1 menjelaskan daftar pertanyaan pada responden. Skala Likert dipergunakan untuk pengukuran atas jawaban dari pernyataan yang diajukan kepada responden penelitian, dengan cara memberikan skor pada setiap item jawaban. Menurut Riduwan dan Sunarto (2014),“Skala Likert digunakan untuk mengukur sikap, pendapat, dan persepsi seseorang atau sekelompok tentang kejadian atau sosial".

Dalam penelitian ini, skor untuk setiap jawaban dari pernyataan yang diajukan kepada responden, mengacu pada Sugiyono (2014) yaitu "Dengan skala Likert, maka variabel yang akan diukur dijabarkan menjadi indikator variabel. Kemudian indikator tersebut

\section{HASIL DAN PEMBAHASAN}

\subsection{Deskripsi responden}

Responden dalam penelitian ini adalah 30 responden yaitu pihak kontraktor pelaksana proyek konstruksi jalan yang memiliki kantor di kota Padang (Sumatera Barat). Karakteristik responden diklasifikasikan berdasarkan pendidikan terakhir (6 orang lulusan D3 dan 24 orang lulusan S1/D4); jabatan responden

\subsection{Pengujian Validitas}

Setiap penelitian yang dilakukan dengan menggunakan metode questionnaire perlu dilakukan uji validitasnya. Sugiyono (2014) menyatakan bahwa "Instrumen yang valid berarti alat ukur yang digunakan untuk dijadikan sebagai titik tolak untuk menyusun item-item instrumen yang dapat berupa pernyataan atau pertanyaan".

Sedangkan nilai persentase yang dipakai untuk menentukan pengaruh risiko pada pelaksanaan proyek konstruksi jalan, yang telah teridentifikasi pada indikator/sub variabel risiko, adalah (Astiti, 2014):

- Sangat kecil $=0 \% \leq-<5 \% \ldots$...(nilai 1)

- Kecil $=5 \% \leq-<15 \% \ldots$.(nilai 2 )

- Sedang $=15 \% \leq-<45 \%$....(nilai 3 )

- Besar $=45 \% \leq-<80 \%$....(nilai 4)

- $\quad$ Sangat besar $=\geq 80 \% \ldots \ldots \ldots \ldots \ldots \ldots .$. (nilai 5$)$

dalam proyek (11 project manager dan 19 site manager); pengalaman perusahaan dalam proyek konstruksi jalan; pengalaman responden dalam melaksanakan proyek konstruksi jalan; jumlah proyek konstruksi jalan yang dilaksanakan perusahaan dalam 5 tahun terakhir; kualifikasi kontraktor (M1, M2, B1) serta bentuk badan usaha perusahaan (26 PT dan $4 \mathrm{CV}$ ).

mendapatkan data (mengukur) itu valid. Valid berarti instrumen tersebut dapat digunakan untuk mengukur apa yang seharusnya diukur". Pengujian validitas diproses dengan SPSS 16, yakni dengan mendeteksi nilai Correted Item Total Correlation hasil output SPSS 16. Jika nilai Corrected Item Total 
Correlation yang diperoleh untuk tiap pernyataan lebih besar dari $r_{\text {tabel }}$ (pada penelitian ini $r_{\text {tabel }}=0.361$ ) maka data valid.

Dari 14 variabel dan 84 sub variabel (indikator) yang tertera di questionnaire pada penelitian ini, semuanya adalah indikator yang valid karena $r_{\text {hitung }}>r_{\text {tabel }}(0.361)$.

\subsection{Pengujian Reliabilitas}

Menurut Sugiyono (2014) reliabilitas adalah "Instrumen yang bila digunakan beberapa kali untuk mengukur obyek yang sama, akan menghasilkan data yang sama".Untuk melihat reliabilitas masing- masing instrumen yang digunakan, penulis menggunakan koefisien Cronbach's alpha (a) dengan menggunakan fasilitas SPSS. Semua sub variabel (84 indikator) penelitian ini adalah reliable. Tabel 2 merupakan hasil pengujian reliabilitas. Kriteria pengujian ini adalah jika nilai koefisien Cronbach's alpha > 0.90 maka reliabilitas sempurna. Jika Cronbach's alpha antara 0.70-0.90 maka reliabilitas dikatakan tinggi. Jika Cronbach's alpha antara $0.50-0.70$ maka reliabilitas moderat/sedang. Jika Cronbach's alpha < 0.50 maka reliabilitas rendah.

Tabel 2. Uji Reliabilitas

\begin{tabular}{||l|l|l|l||}
\hline No & Variabel & Cronbach's alpha & Keterangan \\
\hline 1. & Risiko Alam/Natural (X1) & 0.696 & Sedang \\
\hline 2. & Risiko Sosial (X2) & 0.738 & Tinggi \\
\hline 3. & Risiko Politik (X3) & 0.83 & Tinggi \\
\hline 4. & Risiko Ekonomi (X4) & 0.902 & Sempurna \\
\hline 5. & Risiko Undang-Undang (X5) & 0.955 & Sempurna \\
\hline 6. & Risiko Keselamatan dan Kesehatan Kerja/K3 (X6) & 0.895 & Tinggi \\
\hline 7. & Risiko Manajerial (X7) & 0.92 & Sempurna \\
\hline 8. & Risiko Teknis (X8) & 0.907 & Sempurna \\
\hline 9. & Risiko Budaya (X9) & 0.823 & Tinggi \\
\hline 10. & Risiko Logistik (X10) & 0.865 & Tinggi \\
\hline 11. & Risiko Lingkungan (Kondisi di Sekitar Lokasi & 0.684 & Sedang \\
\hline 12. & Risiko Design dan Technology (X12) & 0.726 & Tinggi \\
\hline 13. & Risiko Tenaga Kerja (X13) & 0.781 & Tinggi \\
\hline 14. & Risiko Kontraktual (X14) & 0.954 & Sempurna \\
\hline
\end{tabular}

\subsection{Analisis Deskriptif}

Analisa deskriptif dilakukan pada penelitian ini. Menurut Sugiyono (2014), "Penelitian deskriptif adalah penelitian yang dilakukan untuk mengetahui keberadaan variabel mandiri, baik hanya pada satu variabel atau lebih tanpa membuat perbandingan atau menghubungkan dengan variabel lain (variabel mandiri adalah variabel yang berdiri sendiri, bukan variabel independen karena jika independen selalu dipasangkan dengan variabel dependen)".

Analisis deskriptif pada penelitian ini hanya berupa nilai rata-rata (mean). Nilai mean dari semua variabel hasil penelitian ini 
dapat dilihat pada Tabel 3. Variabel pertama yaitu variabel risiko alam/natural, terdapat mean tertinggi sebesar 4.11 pada sub variabel X1.5 (Cuaca tidak menentu). Sebagian aktifitas pada pelaksanaan proyek konstruksi jalan sangat sensitif pada cuaca. Contohnya, pekerjaan penghamparan hotmix (pengaspalan) tidak dapat dilakukan dalam kondisi hujan, karena air hujan dapat mempengaruhi kualitas dan ketahanan campuran beraspal (hotmix).
Sedangkan pada variabel risiko sosial terdapat mean tertinggi sebesar 4.1 yaitu sub variabel X2.2 (Masalah lahan/pembebasan lahan area proyek yang direncanakan). Ada kalanya, pada proyek tertentu, pembebasan lahan yang belum tuntas mengakibatkan terhalangnya aktifitas proyek konstruksi jalan. Oleh karena itu, owner harus berusaha membebaskan seluruh lahan untuk proyek konstruksi jalan, sebelum tender pemilihan jasa konstruksi dilakukan.

Tabel 3. Hasil analisis analisa descriptive (mean)

\begin{tabular}{|c|c|c|c|}
\hline $\begin{array}{l}\text { Variabel } \\
\text { bebas }\end{array}$ & $\begin{array}{l}\text { Variabel } \\
\text { resiko }\end{array}$ & Sub variabel resiko & $\begin{array}{c}\text { Analisa } \\
\text { descriptive } \\
\text { (nilai rata-rata) }\end{array}$ \\
\hline $\mathrm{X}_{1.5}$ & Alam/Natural & Cuaca tidak menentu & 4.11 \\
\hline$X_{2.2}$ & Sosial & $\begin{array}{l}\text { Masalah lahan atau pembebasan lahan area } \\
\text { proyek yang direncanakan }\end{array}$ & 4.10 \\
\hline $\mathrm{X}_{3.4}$ & Politik & Aksi mogok kerja oleh pekerja di lapangan & 3.77 \\
\hline $\mathrm{X}_{4.5}$ & Ekonomi & $\begin{array}{l}\text { Aliran dana pelaksanaan proyek dari manajemen } \\
\text { keuangan kontraktor tidak lancar }\end{array}$ & 3.87 \\
\hline$X_{5.2}$ & $\begin{array}{l}\text { Undang- } \\
\text { undang }\end{array}$ & $\begin{array}{l}\text { Kesulitan prosedur dalam menerapkan peraturan } \\
\text { perijinan/UU jasa konstruksi }\end{array}$ & 3.50 \\
\hline $\mathrm{X}_{6.7}$ & $\begin{array}{l}\text { Keselamatan } \\
\text { dan } \\
\text { Kesehatan } \\
\text { Kerja (K3) }\end{array}$ & $\begin{array}{l}\text { Adanya pekerja yang sakit atau mengalami } \\
\text { kecelakaan hingga terjadi kematian }\end{array}$ & 3.70 \\
\hline$X_{7.10}$ & Manajerial & Terhambatnya keuangan pihak kontraktor & 3.77 \\
\hline$X_{8.2}$ & Teknis & $\begin{array}{l}\text { Ketersediaan material yang sampai di lapangan } \\
\text { berbeda dengan yang dipesan }\end{array}$ & 4.17 \\
\hline $\mathrm{X}_{9.1}$ & Budaya & $\begin{array}{l}\text { Komunikasi antara pengawas dengan pekerja } \\
\text { kurang efektif pada saat pelaksanaan proyek }\end{array}$ & 3.4 \\
\hline $\mathrm{X}_{10.4}$ & Logistik & $\begin{array}{l}\text { Tidak ada pengecekan pada saat pengadaan alat } \\
\text { (seperti proses mobilisasi) }\end{array}$ & 3.97 \\
\hline $\mathrm{X}_{11.3}$ & $\begin{array}{l}\text { Lingkungan } \\
\text { (kondisi di } \\
\text { sekitar lokasi } \\
\text { proyek) }\end{array}$ & $\begin{array}{l}\text { Sulitnya (terbatasnya) akses masuk material dan } \\
\text { peralatan ke lokasi proyek }\end{array}$ & 3.70 \\
\hline $\mathrm{X}_{12.1}$ & $\begin{array}{l}\text { Design dan } \\
\text { technology }\end{array}$ & Adanya kesalahan dalam estimasi biaya & 3.73 \\
\hline $\mathrm{X}_{13.4}$ & Tenaga kerja & $\begin{array}{llll}\begin{array}{l}\text { Kurang tersedianya jumlah tenaga kerja } \\
\text { dilapangan }\end{array} & & \\
\end{array}$ & 3.60 \\
\hline $\mathrm{X}_{14.1}$ & Kontraktual & $\begin{array}{l}\text { Pemutusan kerja sepihak oleh owner, jika } \\
\text { kontraktor tidak melaksanakan kewajiban sesuai } \\
\text { kontrak }\end{array}$ & 4.40 \\
\hline
\end{tabular}

Pada variabel yang ke tiga, yakni risiko politik, terdapat mean tertinggi sebesar 3.77 pada sub variabel X3.4 (Aksi mogok kerja oleh pekerja di lapangan). Keinginan tenaga kerja belum tentu sama dengan kebijaksanaan pihak manajemen pelaksana proyek. Sehingga dibutuhkan komunikasi dan human resource management serta rewarding system yang 
dapat memuaskan semua tenaga kerja yang terkait pada pelaksanaan proyek konstruksi jalan.

Mean tertinggi pada variabel risiko ekonomi, yakni sebesar 3.87, terdapat pada sub variabel X4.5. (Aliran dana pelaksanaan proyek dari manajemen keuangan kontraktor tidak lancar). Untuk meminimalisir risiko ini, kontraktor harus membuat perencanaan cash flow (aliran dana uang masuk dan uang keluar) yang efisien dan efektif dengan memperhatikan jadwal pembayaran dari owner.

Pada variabel ke lima, yaitu variabel risiko undang-undang, mean yang tertinggi adalah sebesar 3.50, yakni pada sub variabel X5.2 (Kesulitan prosedur dalam menerapkan peraturan perijinan/UU jasa konstruksi). Hal ini mengingatkan kontraktor untuk menyediakan

Untuk variabel risiko manajerial, mean tertinggi sebesar 3.77 , terdapat pada sub variabel X7.10 (Terhambatnya keuangan pihak kontraktor). Untuk minimalisir risiko ini, sebaiknya kontraktor memiliki modal (aset) yang cukup, agar dapat dipergunakan sewaktu-waktu, untuk mempermudah pelaksanaan proyek konstruksi. Kerjasama kontraktor dengan bank Syariah merupakan salah satu usaha untuk menghindari terjadinya risiko manajerial ini.

Variabel ke delapan adalah risiko teknis, dengan mean tertinggi sebesar 4.17 pada sub variabel X8.2 (Ketersediaan material yang sampai di lapangan berbeda dengan yang dipesan). Perencanaan perhitungan kwantitas material serta jadwal kebutuhan material yang terperinci diperlukan untuk minimalisir risiko ini. Pengontrolan tahapan kebutuhan material dan pengontrolan mutu material, serta koordinasi dengan pihak supplier diperlukan, semua persyaratan dan waktu yang cukup untuk mengurus semua tahapan pada proses perizinan, sehingga dapat melaksanakan semua peraturan proyek konstruksi yang berlaku di Indonesia.

Mean tertinggi sebesar 3.7 pada variabel risiko K3 (Keselamatan dan Kesehatan Kerja) terdapat pada sub variabel X6.7 (Adanya pekerja yang sakit atau mengalami kecelakaan hingga terjadi kematian). Perencanaan sistem manajemen keselamatan dan kesehatan kerja, contohnya construction safety plan di proyek konstruksi jalan harus dibuat dengan terperinci dan sistematis, serta mudah dipahami semua tenaga kerja. Setelah itu, penerapan K3 harus dikontrol secara rutin, serta perlu dilaksanakan safety talk dan safety meeting, untuk menghindari terjadinya kecelakaan kerja.

mulai dari awal proses pengadaan material di lokasi pengambilan material, proses pengangkutan serta penempatan material di construction site, agar material yang sampai di lokasi proyek sesuai dengan spesifikasi teknis, serta kwantitas material tepat sesuai kebutuhan.

Pada variabel risiko budaya terdapat mean tertinggi sebesar 3.40, yakni sub variabel X9.1 (Komunikasi antara pengawas dengan pekerja kurang efektif pada saat pelaksanaan proyek). Kemampuan komunikasi beserta koordinasi dan toleransi antara semua pihak yang terlibat di construction site diperlukan untuk menghindari risiko ini. Kesalahan komunikasi antara pengawas dan pekerja akan mengakibatkan kesalahan pahaman, yang dapat menimbulkan kerugian pelaksanaan proyek konstruksi jalan. Pengetahuan budaya, bahasa daerah dan tradisi masyarakat di sekitar lokasi proyek juga 
dapat mempengaruhi efektifitas komunikasi antara pengawas dan tenaga kerja.

Sedangkan pada variabel risiko logistik terdapat mean tertinggi sebesar 3.97, yaitu sub variabel X10.4 (Tidak ada pengecekan pada saat pengadaan alat (seperti proses mobilisasi)). Salah satu cara untuk menghindari risiko ini adalah koordinasi dengan pihak pemilik alat berat serta pengontrolan mutu kondisi alat berat sebelum proses mobilisasi dimulai.

Mean tertinggi pada variabel risiko lingkungan (kondisi di sekitar lokasi proyek) adalah sebesar 3.70, yakni sub variabel X11.3 (Sulitnya/terbatasnya akses masuk material dan peralatan ke lokasi proyek). Untuk minimalisir risiko ini, maka kontraktor harus mencari solusi terbaik dengan mengoptimalkan penggunaan fasilitas infrastruktur di sekitar lokasi proyek, agar tersedia akses masuk yang dapat memenuhi kebutuhan pelaksanaan proyek. Selain itu, manajemen lalu lintas yang efisien, efektif dan sistematis dibutuhkan pada proyek peningkatan jalan, agar aktivitas kendaraan (arus lalu lintas) yang tetap berjalan di sekitar lokasi proyek tidak mengganggu aktifitas pelaksanaan proyek konstruksi jalan.

Selanjutnya, pada variabel risiko design dan technology, mean tertinggi sebesar 3.73 pada sub variabel X12.1 (Adanya kesalahan dalam estimasi biaya). Salah satu usaha untuk minimalisir risiko ini adalah dengan perencanaan estimasi biaya yang teliti dan sedetail mungkin, serta terintegrasi dengan perencanaan penjadwalan pelaksanaan yang efisien dan efektif, sebelum proses pelaksanaan proyek konstruksi jalan dilaksanakan. Selain itu, kontraktor perlu identifikasi produktifitas tenaga kerja penentu atau produktifitas peralatan penentu untuk setiap item pekerjaan. Kesalahan dalam menganalisa produktifitas penentu akan mengakibatkan kesalahan dalam menghitung estimasi biaya dan juga kesalahan merencanakan durasi item pekerjaan.

Pada variabel risiko tenaga kerja, terdapat mean tertinggi sebesar 3.60 pada sub variabel X13.4 (Kurang tersedianya jumlah tenaga kerja di lapangan). Risiko ini dapat diminimalisir dengan perhitungan produktifitas tenaga kerja sesuai dengan kemampuan tenaga kerja yang tersedia di construction site. Sehingga, jumlah kebutuhan tenaga kerja telah dideteksi sebelum memulai pelaksanaan proyek. Jika dibutuhkan, kontraktor mendatangkan tenaga kerja dari daerah lain sebelum pelaksanaan proyek. Selain itu, dibutuhkan perencanaan jadwal tenaga kerja yang terperinci dan sistematis. Perataan jumlah tenaga kerja (metoda resource leveling), dengan memanfaatkan durasi total float pada item kegiatan yang tidak kritis, dapat diterapkan untuk membuat jadwal tenaga kerja yang optimal.

Sedangkan pada variabel yang terakhir, yaitu variabel risiko kontraktual terdapat mean tertinggi sebesar 4.40, pada sub variabel X14.1 (Pemutusan kerja sepihak oleh owner, jika kontraktor tidak melaksanakan kewajiban sesuai kontrak). Sebelum pemutusan hubungan kerja, owner akan memberi beberapa kali peringatan kepada kontraktor, apabila kontraktor melakukan kesalahan (pelanggaran kontrak). Untuk menghindari risiko ini, kontraktor harus selalu melakukan pengontrolan pelaksanaan seluruh tahapan pekerjaan secara rutin, agar dapat melaksanakan kewajiban sesuai kontrak. Jika menerima peringatan dari owner, kontraktor 
harus segera melakukan evaluasi diri dan mencari solusi terbaik untuk memperbaiki kesalahan sedini mungkin, sehingga risiko pemutusan kontrak kerja oleh owner dapat dihindari.

\section{KESIMPULAN}

1. Penelitian ini mengidentifikasi 14 variabel risiko yang berpengaruh terhadap pelaksanaan proyek konstruksi jalan, yaitu variabel risiko alam/natural, risiko sosial, risiko politik, risiko ekonomi, risiko undang-undang, risiko Keselamatan dan Kesehatan Kerja (K3), risiko manajerial, risiko teknis, risiko budaya, risiko logistik, risiko lingkungan (kondisi di sekitar lokasi proyek), risiko design dan technology, risiko tenaga kerja, serta risiko kontraktual. Semua 84 sub variabel

\section{DAFTAR PUSTAKA}

Ari Sandhyavitri dan Muhammad Zulfiqar, "Analisis Risiko Pembangunan Jalan Tol pada Tahap Konstruksi (Studi Kasus Jalan Tol Pekanbaru-Dumai)", Jurnal Teknik Sipil Vol.10 Nomor 1, Fakultas Teknik, Universitas Riau, Pekanbaru, April 2014

Donald S. Barrie and Boyd C. Paulson, Jr., "Professional Construction Management: Including CM, DesignConstruct, and General Contracting", $3^{\text {rd }}$ ed., Mc Graw Hill, USA, 1992

Iman Suharto, "Manajemen Proyek: dari Konseptual Sampai Operasional", Erlangga, Jakarta, 1995

Mastura Labombang, "Manajemen Risiko dalam Proyek Konstruksi", Jurnal SMARTek, Vol. 9 No. 1. Februari 2011

Ni Putu Mega Astiti, "Analisis Risiko Pelaksanaan Pembangunan Jalan Tol Benoa-Bandara-Nusa Dua", Magister Thesis, Universitas Udayana, Denpasar, 2014 (indikator) pada questionnaire penelitian ini adalah valid dan reliable.

2. Variabel risiko yang paling berpengaruh pada pelaksanaan proyek konstruksi jalan, yang merupakan tiga nilai rata-rata (mean) teratas pada hasil analisis penelitian ini adalah variabel risiko kontraktual dengan sub variabel pemutusan kerja sepihak oleh owner jika kontraktor tidak melaksanakan kewajiban sesuai kontrak (mean 4.4); variabel risiko teknis dengan sub variabel ketersediaan material yang sampai di lapangan berbeda dengan yang dipesan (mean 4.17) ; variabel risiko alam/natural dengan sub variabel cuaca yang tidak menentu (mean 4.11)

Pricillia Syaranamual, Patrick Tandean, dan Herry P. Chandra, "Model Faktor Penyebab Risiko terhadap Keberhasilan Proyek Konstruksi", Jurnal Dimensi Pratama Teknik Sipil, Vol. 3 No. 2, Surabaya, 2014

Rahmanita Sujatsi, I Putu Artama Wiguna, dan A.Agung G. Kartika, "Analisa Risiko Performance Based Contract pada Pemeliharaan Jalan Nasional", Prosiding Seminar Nasional Manajemen Teknologi XX Program Studi MMT-ITS, Surabaya 1 Februari 2014

Riduwan dan Sunarto, "Pengantar Statistika untuk Penelitian Pendidikan, Sosial, Ekonomi, komunikasi dan Bisnis", Alfabeta, Bandung, 2014

Sugiyono, "Metode Penelitian Pendidikan Pendekatan Kuantitatif, Kualitatif Dan R\&D”, Alfabeta, Bandung, 2014

Syofyan Yamin dan Heri Kurniawan, "SPSS Complete: Teknik Analisis Statistik Terlengkap dengan software SPSS", Salemba Infotek, Jakarta Selatan, 2013 